\title{
autêntica
}

\section{ARTIGOS \\ PRÁTICA DOCENTE NA EDUCAÇÃO \\ PROFISSIONAL E TECNOLÓGICA: OS \\ CONHECIMENTOS QUE SUBSIDIAM OS PROFESSORES DECURSOS TÉCNICOS}

Geralda Aparecida de Carvalho Pena

\begin{abstract}
RESUMO: Este trabalho tem como objetivo discutir a docência na Educação Profissional e Tecnológica (EPT), buscando identificar e analisar os conhecimentos que subsidiam a prática docente na EPT, mais especificamente nos cursos técnicos de nível médio, no ensino das disciplinas técnicas. Para isso, são apresentados alguns resultados de uma tese que investiga os conhecimentos, as práticas e os desafios da docência da Educação Profissional e Tecnológica no contexto de um Instituto Federal de Educação, Ciência e Tecnologia. A pesquisa foi desenvolvida por meio de um estudo de caso que utilizou como instrumentos de coleta de dados, em sua primeira etapa, questionários e análise documental e, na segunda etapa, observações da prática docente e entrevistas. Neste artigo, foi feito um recorte de forma a apresentar e analisar parte dos dados obtidos nas entrevistas realizadas com seis professores de cursos técnicos de nível médio com formação em cursos de pós-graduação, mas sem formação para o ensino e com tempos diferenciados de experiência docente. Os dados mostram que a prática docente na EPT é resultante da articulação de diversos tipos de conhecimentos, valorizados de forma diferenciada pelos professores, que dão maior destaque ao conhecimento do conteúdo e ao conhecimento prático na área de trabalho em que se insere o curso técnico e menor ênfase ao conhecimento pedagógico. A análise aponta elementos para aprofundar a problematização e a reflexão sobre a constituição da prática docente dos professores da EPT e sobre seu processo de formação.
\end{abstract}

PALAVRAS-CHAVE: Docência na EPT; Ensino; Disciplinas técnicas.

\section{ABSTRACT}

This work aims at discussing teaching in the professional and technological education (PTE), seeking to identify and analyze the knowledge that underlies the teaching practice in PTE, more specifically in technical secondary school courses in the teaching of technical subjects. This study presents some results of a dissertation that investigates the knowledge, practices and challenges of teaching in the PTE, in a Federal Institute of Education, Science and Technology. The survey was developed through a case study that used, in its first stage, questionnaires and documentary analysis and, in the second step, classroom observations and interviews as data collection instruments. For this paper, it was made a cutout in order to present and analyze some of the data obtained from the interviews that were conducted with six teachers. They all teach in the technical secondary school courses, have different years of work experience, have been enrolled in post graduation programs, but without teaching training. The data show that the teaching practice in PTE is resulting from the combination of different types of knowledge, which are valued differently by the teachers, that give greater emphasis to content and practical knowledge in the technical course local context, and less emphasis on pedagogical knowledge. The analysis points to the need of further questioning and reflection about the constitution of teaching practice of PTE teachers and about their training process.

KEYWORDS: Teaching at PTE; Teaching; Technical subjects. 


\section{autêntica}

\section{INTRODUÇÃO}

A Educação Profissional e Tecnológica (EPT) é definida na Lei de Diretrizes e Bases da Educação Nacional (Lei n. ${ }^{\circ}$ 9.394/96) (BRASIL, 1996), atualizada pela Lei n. ${ }^{\circ} 11.741 / 2008,{ }^{1}$ no artigo 39, da seguinte forma: "A educação profissional e tecnológica, no cumprimento dos objetivos da educação nacional, integra-se aos diferentes níveis e modalidades de educação e às dimensões do trabalho, da ciência e da tecnologia". Por essa lei, a EPT é uma modalidade de educação que abrange os seguintes cursos:1) formação inicial e continuada ou qualificação profissional;2) educação profissional técnica de nível médio e 3) educação profissional tecnológica de graduação e pós-graduação (parágrafo $2^{\circ}$, incisos I, II e III). Em cada nível/modalidade de ensino há especificidades relacionadas a diferentes elementos e às suas formas de organização, que apresentam diversidade de modalidades, de currículos, de relação com os setores econômicos, de eixos tecnológicos, de rede de escolas, de instâncias mantenedoras, etc. Dois aspectos se apresentam na organização dos cursos técnicos: a variedade de currículos ofertados nesses cursos em cada modalidade de ensino (integrado, concomitante ou subsequente ao ensino médio) e a heterogeneidade do perfil dos alunos que frequentam cada tipo de curso, o que apresenta demandas diferenciadas de trabalho ao professor.

Não obstante essa diversidade na forma de organização, a docência na EPT ainda é pouco investigada no Brasil. Os estudos atuais mostram que há especificidades que precisam ser consideradas tanto no que se refere à docência nesse contexto quanto à formação docente para os professores de EPT, uma vez que o desenvolvimento da prática docente nesses cursos precisa levar em conta a complexidade desse universo e as necessidades de cada uma das formas organizativas dessa modalidade de ensino, bem como a articulação com o mundo do trabalho, que demanda atenção constante à relação teoria/prática, entre outros aspectos. Mediante o exposto, emergem as seguintes questões: o que caracteriza a docência na EPT? Na organização da prática docente para o ensino das disciplinas técnicas, que tipos de conhecimentos os professores utilizam como referência? Que processos formativos decorrentes da trajetória acadêmica e profissional dos docentes Ihes possibilitaram a construção de conhecimentos necessários ao ensino?

Busca-se neste artigo identificar e analisar os conhecimentos que subsidiam a prática docente na EPT, mais especificamente nos cursos técnicos de nível médio, tendo como foco de análise o ensino das disciplinas técnicas, que se caracterizam por fornecer os conhecimentos específicos que visam à formação do aluno para o mundo do trabalho. ${ }^{2}$ Para isso, são apresentados parte dos resultados de uma pesquisa de doutorado que investiga os conhecimentos, as práticas e os desafios da docência na Educação Profissional e Tecnológica.

\section{PRÁTICA DOCENTE NA EDUCAÇÃO PROFISSIONAL E TECNOLÓGICA: REFLEXÕES INICIAIS}

A análise da docência na EPT mostra aspectos específicos dessa modalidade de ensino, em que elementos variados demarcam diferenças significativas em relação, por exemplo, ao perfil do profissional que atua como docente dos cursos técnicos. Na Rede Federal de Educação Profissional, Científica eTecnológica geralmente exige-se, nos concursos públicos, a formação em curso de graduação na área específica do conhecimento em que o professor vai atuar, sendo bastante valorizada a formação em nível de pós-graduação stricto sensu. Já nas escolas privadas, normalmente na contratação de professores é priorizada a experiência profissional na indústria, focalizando o aspecto prático, relacionado ao exercício profissional. Essas diferenças se fazem

\footnotetext{
1 “Altera dispositivos da Lei n.o 9.394, de 20 de dezembro de 1996, para redimensionar, institucionalizar e integrar as ações da educação profissional técnica de nível médio, da educação de jovens e adultos e da educação profissional e tecnológica.” (BRASIL, 2008)

2 Também denominadas, em outros estudos, “disciplinas de formação específica”, "disciplinas profissionalizantes”, “disciplinas das áreas tecnológicas”.
} 


\section{autêntica}

notar também no que se refere ao regime e às condições de trabalho dos professores. Observando-se o corpo docente das disciplinas técnicas dos cursos de EPT de nível médio na Rede Federal, pode-se constatar que ele é composto, em sua maioria, por profissionais com diferentes formações, como engenharia, administração, turismo, enfermagem, nutrição, entre outras. Grande parte desses profissionais possui qualificação em cursos de mestrado e doutorado em suas áreas de conhecimento específico e ingressaram no magistério com pouca ou nenhuma referência pedagógica mais sistematizada. Conforme afirmam Kuenzer, Franco e Machado (2006), os cursos de mestrado e doutorado, por estarem mais centrados na pesquisa, não têm formado professores, dando pouca ou nenhuma ênfase à formação pedagógica. Essa situação levanta as seguintes questões: de que forma esse profissional, que não teve uma formação voltada para o processo de ensinar, desenvolve sua prática docente? Ao assumir a condição de docente, que referências utiliza para ensinar?

Uma análise da legislação da educação no Brasil revela que não há, de forma explícita, exigência de requisitos legais de formação docente para atuar na EPT, visto que a LDB em vigor (Lei n. ${ }^{\circ}$ 9.394/96) estabelece diretrizes para a formação de docentes para atuar na educação básica e na educação superior, mas não menciona diretamente a formação dos professores para a EPT. Analisando ainda as legislações específicas referentes à EPT no Brasil (decretos e pareceres), constata-se que o que prevalece é a falta de definições relativas à formação desses profissionais. Ainda que haja essa ambiguidade legal em relação à formação dos professores da EPT, o que acontece na prática é que a maior parte desses professores não possui formação voltada para o ensino, de acordo com a Sinopse Estatística da Educação Básica 2013 (BRASIL, 2013), ${ }^{3}$ publicada pelo Instituto Nacional de Estudos e Pesquisas Educacionais Anísio Teixeira (INEP). Essa ausência de formação docente, evidenciada nos dados oficiais e nos estudos da área de formação de professores, constitui-se em um fator importante para a busca de maior compreensão da docência nessa modalidade de ensino. Para Machado (2008), a docência na EPT tem como especificidade primeira a tecnologia, que se configura como uma ciência transdisciplinar das atividades humanas de produção, do uso dos objetos técnicos e dos fatos tecnológicos. A autora enfatiza que:

Os professores da educação profissional enfrentam novos desafios relacionados às mudanças organizacionais que afetam as relações profissionais, aos efeitos das inovações tecnológicas sobre as atividades de trabalho e culturas profissionais, ao novo papel que os sistemas simbólicos desempenham na estruturação do mundo do trabalho, ao aumento das exigências de qualidade na produção e nos serviços, à exigência de maior atenção à justiça social, às questões éticas e de sustentabilidade ambiental. São novas demandas à construção e reestruturação dos saberes e conhecimentos fundamentais à análise, reflexão e intervenções críticas e criativas na atividade de trabalho (MACHADO, 2008, p. 15).

Assim, a docência na EPT apresenta questões que demandam dos professores conhecimentos que viabilizem aos alunos uma formação que não se limita a uma concepção de formação técnica vinculada ao mero treinamento, mas que seja direcionada por uma concepção mais ampla do ensino no contexto atual. De acordo com Oliveira (2000), a formação dos alunos nas escolas de EPT deve se pautar pela concepção de educação tecnológica, que, no dizer da autora, não se resumiria a uma formação voltada apenas para o domínio das técnicas de execução de atividades e tarefas no setor produtivo e de serviços, mas

\footnotetext{
${ }^{3}$ Dados da Sinopse Estatística da Educação Básica de 2013apontam que, do total de 73.904 professores da EPT de diferentes esferas (federal, estadual, municipal e privada), 65.718 possuem curso superior e, desses, apenas 18.659 possuem cursos com licenciatura. Pode-se inferir que, se forem considerados somente os professores das disciplinas técnicas, esse valor seja ainda menor.
} 


\section{autêntica}

[...] envolveria, entre outros, o compromisso com o domínio, por parte do trabalhador, dos processos físicos e organizacionais ligados aos arranjos materiais e sociais e do conhecimento aplicado e aplicável, pelo domínio dos princípios científicos e tecnológicos próprios a um determinado ramo de atividade humana (OLIVEIRA, 2000, p. 42).

Oliveira e Burnier (2013) ressaltam a necessidade de que a formação tecnológica possibilite ao aluno não apenas o uso das tecnologias, mas também a reflexão crítica sobre elas, o que pressupõe a "defesa de uma educação profissional, científica e tecnológica não meramente técnica, e comprometida com a formação omnilateral de seus sujeitos" (OLIVEIRA e BURNIER, 2013, p.149). Uma formação com base nesses pressupostos implica considerar as concepções dos professores sobre a função social da educação e da educação tecnológica, bem como os contextos específicos nos quais o trabalho docente na EPT se desenvolve, que conferem aos docentes elementos e/ou determinantes para além das características comuns ao trabalho docente em geral, caracterizando sua especificidade.

Melo (2010) afirma que a complexidade do trabalho docente, decorrente de transformações trazidas pelas novas políticas educacionais que implicaram mudanças na organização escolar, comum a outros níveis de ensino, se amplia quando se volta o olhar para o trabalho docente na EPT. Ela argumenta que a própria natureza da educação tecnológica compreende diferentes atividades teóricas e práticas e necessita de espaços físicos diferenciados que vão além de salas de aula, tais como laboratórios, oficinas e, muitas vezes, aulas em outros ambientes externos do campo profissional, o que apresenta novas exigências ao trabalho dos professores. Além disso, outro fator mencionado pela autora é a dificuldade de articulação ou integração entre o ensino acadêmico e o ensino profissionalizante, que se manifesta por meio da variedade de modalidades de oferta, da desarticulação de currículos e das extensas jornadas de atividades discentes, o que contribui para o isolamento entre os professores da área básica e os da área técnica que desenvolvem o trabalho docente na mesma instituição, "caracterizando disputas por ocupação de espaços, tempos e conteúdos nos cursos, que denotam disputas por poder e status" (MELO, 2010, p.3).

A atuação dos professores da EPT, para Machado (2008), precisa levar em conta a complexidade desse universo e as necessidades de cada uma das formas organizativas dessa modalidade de ensino. Em meio a essa complexidade de situações presentes na docência na EPT, pode-se dizer que, além desses aspectos, é necessária ainda atenção a outras peculiaridades dessa modalidade de ensino: a concepção de educação técnica e tecnológica que permeia a prática docente; a formação de profissionais para atuação no mundo do trabalho; e as especificidades dos eixos tecnológicos que definem o currículo dos cursos técnicos, ${ }^{4}$ bem como seus aspectos legais. Além disso, não podem ser desconsideradas as particularidades da Rede Federal de EPT, que possui singularidades decorrentes de sua cultura organizacional que carrega uma tradição histórica centenária e das influências dessa cultura na prática docente. E quais as demandas que essas especificidades colocam para a docência nesse contexto? Que elementos os professores da EPT precisam considerar ao organizar o trabalho docente nos cursos técnicos? Que conhecimentos subsidiam sua prática no ensino das disciplinas técnicas? Este artigo busca identificar e analisar tais conhecimentos e a relação entre eles na constituição da prática docente, bem como oferecer elementos para aprofundar a problematização e a reflexão sobre a prática docente dos professores da EPT.

\footnotetext{
${ }^{4}$ O Catálogo Nacional de Cursos Técnicos se constitui como referência e fonte de orientação para a oferta dos cursos técnicos no país, contempla 220 cursos, distribuídos em 13 eixos tecnológicos. BRASIL. Ministério da Educação. Conselho Nacional de Educação. Câmara de Educação Básica. Resolução ${ }^{\circ}$ 4, de 6 de junho de 2012. Dispõe sobre alteração na Resolução CNE/CEB n n 3/2008, definindo a nova versão do Catálogo Nacional de Cursos Técnicos de Nível Médio. Disponível em: Acesso em 20/07/2012
} 


\section{autêntica}

\section{PERCURSO METODOLÓGICO DA PESQUISA}

A pesquisa foi realizada usando uma abordagem qualitativa (ANDRÉ, 2005, 2008; BOGDAN; BIKLEN, 1994; POUPART et al., 2010, entre outros) e um estudo de caso (ANDRÉ, 2005) foi feito, buscando investigar as várias dimensões presentes na prática docente dos professores, de forma a compreender a docência na EPT. Após um mapeamento geral do perfil dos professores das disciplinas técnicas da instituição, foram selecionados seis docentes para viabilizar o aprofundamento da investigação. Em uma primeira etapa, utilizou-se de questionários e análise documental, instrumentos que possibilitaram caracterizar a instituição e traçar o perfil dos docentes das disciplinas técnicas.

Dos 174 professores, considerando todos os níveis de ensino ofertados na instituição, 67 são das disciplinas técnicas, sendo que, desses, 48 são efetivos, ${ }^{5}$ dos quais quase $70 \%$ são mestres ou doutores. Esses dados apontam um corpo docente qualificado, considerando as exigências para o magistério no ensino médio. Os48 professores efetivos foram os sujeitos da pesquisa em sua primeira fase, e 6 deles foram selecionados para a segunda fase, na qual foram realizadas a observação da prática docente e as entrevistas.

A pesquisa foi realizada no Instituto Federal Minas Gerais, campus Ouro Preto, uma instituição da Rede Federal de Educação Profissional, Científica e Tecnológica de referência na formação profissional, que tem 70 anos de tradição no ensino de qualidade na região, principalmente no ensino técnico, que é oferecido desde sua criação, em 1944. A instituição atende mais de 3.000 alunos, distribuídos em sete cursos técnicos integrados, cinco cursos técnicos subsequentes e cinco cursos superiores, sendo três de tecnologia e dois de licenciatura, além de oferecer também cursos técnicos na modalidade a distância. Trata-se de uma estrutura organizacional complexa que tem vivenciado um cenário em que novas exigências se apresentam ao trabalho docente em decorrência da sua transformação em Instituto Federal. Nesse contexto, o exercício profissional, que antes tinha foco mais direcionado ao ensino, estende-se às atividades de pesquisa e extensão, e se amplia tendo em vista a verticalização do ensino. É nessa instituição, em que uma cultura institucional própria e diferenciada se configura e influencia ou determina as relações que aí se desenvolvem, que foi realizado o estudo.

Neste artigo, foi feito um recorte da tese de doutoramento da autora ${ }^{6}$ de forma a apresentar e analisar parte dos dados obtidos nas entrevistas, ${ }^{7}$ mais especificamente as questões que buscaram identificar os conhecimentos que informam ou subsidiam a prática docente nessa modalidade de ensino. Foram entrevistados professores de quatro cursos técnicos, com tempos diferenciados de experiência docente na instituição, configurando uma amostra composta por seis professores com idade entre 36 e 57 anos e que possuíam, na época da pesquisa, entre 5 e 26 anos de experiência docente na instituição. Esses professores lecionam nos cursos técnicos de Automação Industrial, Edificações, Metalurgia e Mineração, nas modalidades integrada ou subsequente ao ensino médio. Todos os professores são do sexo masculino e trabalham em regime de dedicação exclusiva na instituição. Entre as demais características, é importante ressaltar que todos têm graduação em Engenharia, dois professores possuem o título de doutor e quatro, de mestre. Desses, um estava cursando doutorado no momento de realização da pesquisa. Nenhum deles possui formação voltada

\footnotetext{
5 Dados coletados no Sistema Acadêmico do Instituto Federal Minas Gerais - campus Ouro Preto. Disponível em: <www.cefetop.edu.br>. Acesso em: 27 fev. 2011.

${ }^{6}$ PENA, G. A. C. Docência na educação profissional e tecnológica: conhecimentos, práticas e desafios de professores de cursos técnicos na rede federal. Tese (Doutorado em Educação) - Faculdade de Educação, Universidade Federal de Minas Gerais, Belo Horizonte - MG, 2014.

7 As entrevistas buscaram abordar as situações de ensino observadas em sala de aula, as formas de organização e as estratégias de ensino, os conhecimentos que subsidiam o ensino na EPT e as fontes desses conhecimentos, bem como diferentes aspectos da trajetória acadêmica e profissional dos professores.
} 


\section{autêntica}

para o ensino, como cursos de licenciatura ou o Programa de Formação Pedagógica para Docentes. Cinco professores realizaram o curso técnico de nível médio na mesma área em que atuam como professores, sendo quatro ex-alunos da instituição onde trabalham como docentes.

\section{CONHECIMENTOS EM AÇÃO NO ENSINO DAS DISCIPLINAS TÉCNICAS}

Diferentes autores têm estudado os conhecimentos/saberes necessários aos professores para realizar as atividades de ensino. Para Shulman (2005b), existe uma base de conhecimentos para o ensino que se configura com os seguintes tipos de saberes: conhecimento do conteúdo, conhecimento pedagógico geral, conhecimento do currículo, conhecimento pedagógico do conteúdo, conhecimento dos alunos e de suas características, conhecimento dos contextos educativos e conhecimento dos objetivos, das finalidades e dos valores educacionais e de seus fundamentos filosóficos e históricos (SHULMAN, 2005b, p.11, tradução nossa). Nesta pesquisa, considerando os estudos sobre a docência na EPT e o perfil dos professores que lecionam nessa modalidade de ensino, procurou-se investigar os conhecimentos que subsidiam o trabalho docente no ensino das disciplinas técnicas.

Os seis professores entrevistados mencionaram diferentes tipos de conhecimentos, destacando como primeiro elemento relevante para a prática docente o conhecimento dos conteúdos ensinados. Esse conhecimento - adquirido na formação acadêmica, nos cursos de graduação e pós-graduação -, no entendimento dos professores, precisa ser profundo e viabilizar ao docente não só conhecer a(s) disciplina(s) com as quais trabalha, mas também inserir-se no contexto amplo do seu campo de estudos, considerando aspectos históricos e conceituais que Ihe proporcione uma sólida formação. O professor Breno8ressalta a importância desse tipo de conhecimento e de sua atualização: "O professor tem que saber muito o que ele vai ensinar. [...] Ele tem que ter o conhecimento técnico da área que ele vai ministrar, tem que estar antenado com as novas tecnologias e sempre se atualizando e buscando novas referências". Além do conhecimento do conteúdo referente à disciplina, Henrique ressalta a importância de o professor estabelecer relações entre a disciplina que leciona e as demais do seu campo de conhecimento: "Tem que ter um embasamento enorme de toda aquela cadeia que vai precisar naquela disciplina, não só ser um conhecedor da disciplina, precisa saber a aplicação, pôr a mão na massa...."Esse conhecimento mais amplo da área em que atua é considerado importante também por João, que entende ser necessário ainda o conhecimento global do curso como um todo. Leonardo considera indispensável para o ensino a posse do conhecimento técnico abrangente da área em que atua, aliado à capacidade de transmitir o conhecimento de uma forma que o outro aprenda. Vinícius entende ser fundamental, além do conhecimento profundo da disciplina, a experiência prática na área em que se insere o conteúdo ensinado.

As afirmações dos professores vão ao encontro da posição de Shulman (2005b), para quem a primeira fonte do conhecimento base para o ensino é o conhecimento do conteúdo da disciplina que se vai ensinar. Para o autor, é esse conhecimento que viabiliza ao professor saber os princípios conceituais e as estruturas da matéria, os aspectos centrais do conteúdo, as habilidades e as disposições que os alunos devem adquirir durante o ensino. Sendo assim, afirma que o conhecimento do conteúdo ocupa lugar central na base de conhecimentos necessários ao ensino, não devendo se ater, entretanto, à(s) disciplina(s) que o professor ministra, mas estar relacionado ao seu campo de atuação e ao conhecimento global do curso, fato ressaltado pelos docentes. 


\section{autêntica}

A formação obtida pelos professores em sua trajetória acadêmica, nos cursos de graduação e pós-graduação, é o primeiro aspecto mencionado por eles como fonte para a aquisição/construção de conhecimentos para ensinar, o lugar primordial de adquirir o conhecimento do conteúdo, que se mostra como fundamental para o exercício da docência na EPT. Esse tipo de conhecimento, de acordo com os professores, deve ser constantemente atualizado, isto é, eles devem estar "antenados com as novas tecnologias" via cursos, leituras de livros e revistas, estudos, acesso a sites de empresas, entre outros. Além disso, a atualização é considerada relevante para o conhecimento dos cenários do trabalho de seu campo profissional, elemento importante para viabilizar discussões com os alunos nas aulas dos cursos técnicos.

Rehem (2005) afirma que o ensino de uma profissão demanda a capacidade de situar-se no contexto dela com suas exigências no mundo contemporâneo. Nesse sentido, diz que

[...] ensinar a trabalhar numa dada área requer necessariamente saber como se dá o trabalho naquela área, seus processos produtivos, suas exigências reais, suas contradições, seus avanços tecnológicos, suas tendências, suas relações no mercado de trabalho (REHEM, 2005, p. 90).

De acordo com a autora, é necessário que o professor do ensino técnico domine os princípios que estruturam a prática em sala de aula, o mercado de trabalho, os setores produtivos e a sociedade, de forma a conduzir o trabalho formativo de modo crítico e reflexivo, comprometido com a formação de pessoas também críticas. Essa seria uma condição importante para que o professor pudesse desenvolver seu trabalho "transformando conteúdos de sua formação específica em conteúdos ensináveis de forma contextualizada no mundo do trabalho, na perspectiva do ensino" (REHEM, 2005, p.100).

O outro tipo de conhecimento elencado pelos professores é o conhecimento prático da área de trabalho em que se insere o curso técnico. No dizer dos professores pesquisados, aliado ao conhecimento do conteúdo, adquirido durante a formação acadêmica, a experiência prática de trabalho como técnico ou engenheiro em empresas ou o conhecimento da realidade desse tipo de trabalho, futuro campo de atuação profissional dos alunos, constitui-se em outro importante conhecimento para a docência na EPT. A relevância conferida a esse conhecimento foi destacada por todos os professores. João acredita que não basta o conhecimento da disciplina que se vai lecionar e um conhecimento amplo do curso em que atua, é importante que o professor tenha também vivenciado a profissão: "A vivência profissional é muito importante. Um professor que tenha muita experiência na indústria, pra dar aula pro curso técnico, traz muito mais bagagem do que um professor que é só acadêmico, que nunca atuou". Para esse professor, a experiência prática se destaca pelo poder de viabilizar a utilização, durante as aulas, de exemplos de situações relativas aos processos de trabalho do futuro profissional que está em formação.

A experiência profissional de trabalho na área em que atua como docente, para Rafael, envolve o trabalho do professor não só em empresas, mas também a sua inserção em projetos sociais, culturais, políticos e técnicos fora da escola. "Não tenho a menor dúvida que a experiência de trabalho e a convivência externa ajudam o professor na sua atividade de dar aula". De acordo com o professor, o regime de trabalho de dedicação exclusiva impõe limitações ao docente no sentido de desenvolver outras atividades de trabalho concomitantes ao ensino, mas, no seu entendimento, a atuação em projetos de extensão, que é uma das demandas dos Institutos Federais, constitui-se em uma forma de o professor se inserir em atividades profissionais de sua área de atuação fora da docência, visando obter contribuições para o trabalho docente. Henrique também considera importante que o professor tenha outras experiências em sua área profissional fora da docência. Considerando que o regime de dedicação exclusiva não possibilita a realização de trabalho paralelo ao ensino, ele ressalta a relevância de períodos de formação em ambientes de trabalho relacionados à engenharia. 


\section{autêntica}

A importância do conhecimento prático para o ensino das disciplinas técnicas foi ressaltada até mesmo pelos professores que não tiveram experiências anteriores de trabalho em empresas, como Breno, Leonardo e Vinícius, pois segundo eles é possível adquirir tal conhecimento utilizando outras formas de inserção no mundo do trabalho, como realização de projetos de pesquisas e de extensão. Breno considera importante que o professor de disciplina técnica tenha conhecimento do processo de trabalho dentro da empresa que se constituirá em futuro campo de atuação profissional de seus alunos, pois tal conhecimento é essencial para que o professor possa contextualizar o ensino em sala de aula, trazendo exemplos do mundo do trabalho e analisando de forma crítica determinadas situações. Os conhecimentos adquiridos/construídos por ele na área de pesquisa são utilizados em sala de aula no curso de Mineração, tanto nas explicações que fornece aos alunos sobre os processos que ocorrem na mineradora quanto em vídeos que apresentam tais processos.

A pesquisa mostrou que esse conhecimento prático, adquirido mediante a vinculação com o mundo do trabalho, ocorreu para todos os professores, ainda que em diferentes tipos de experiências. Os professores Rafael, João e Henrique tiveram uma atuação profissional anterior à docência como técnicos ou engenheiros, assim a relação com o mundo do trabalho constituiu-se pela via da atuação profissional. Os professores Breno, Leonardo e Vinícius, que não trabalharam em empresas anteriormente à sua atividade docente, cursaram o mestrado (e doutorado, no caso de Vinícius) na área específica em que lecionam, ou seja, tiveram uma inserção no campo do trabalho em que atuam como docentes pela via acadêmica, fazendo pesquisa na pós-graduação. Esse tipo de conhecimento foi destacado por todos como relevante para viabilizar ao professor fontes de exemplos, ilustrações e analogias que contribuem para enriquecer as aulas e facilitar a aprendizagem dos alunos, com a utilização constante de referências ao trabalho prático e real, objetivando levar para a sala de aula situações concretas da futura prática profissional dos alunos.

Tais especificidades em relação aos conhecimentos necessários para a docência de disciplinas técnicas da EPT são apontadas também nos estudos de Kuenzer (2010), que defende a articulação entre o conhecimento científico e o conhecimento prático no ensino das disciplinas da EPT.

A transposição didática não será eficiente se contemplar apenas a dimensão intelectual do trabalho a ser ensinado, o que significa que o professor deverá ter experimentado, em algum momento de sua trajetória, e de alguma forma, a prática do trabalho que se propõe a ensinar (KUENZER, 2010, p. 506).

Segundo a autora, a experiência no/com o mundo do trabalho é imprescindível para o professor de disciplinas técnicas, sendo necessária para a qualidade do docente da EPT. Ela argumenta que

[...] não basta a formação teórica, pois ao professor é necessário que domine, para ensinar, como o conhecimento científico fundamenta a prática laboral, conferindo significado e materialidade aos conceitos. Na formação, este movimento se dá do raciocínio científico para a prática, via transposição didática, que deverá incluir atividades que insiram o estudante na realidade do trabalho: laboratórios, casos, visitas, estágios, pesquisas de campo (KUENZER, 2010, p. 508-509).

Os dados ora apresentados parecem apontar para a possibilidade de que a imersão no campo de trabalho em que o professor atua viabilize experiências que contribuam para o fazer pedagógico na EPT, confirmando a constatação sobrea importância da inserção no mundo do trabalho e a relevância atribuída ao conhecimento prático na área tecnológica para a docência na EPT em outras pesquisas. ${ }^{9}$ 


\section{autêntica}

$\mathrm{Na}$ análise da relevância dos conhecimentos relacionados ao mundo do trabalho para a docência na EPT, os aspectos levantados pelos professores abordaram a questão da importância desse tipo de conhecimento para fundamentar contextualizações do ensino com a atividade laboral do técnico de nível médio, tendo como base as situações concretas vivenciadas por eles em diferentes períodos de sua trajetória profissional. Dois professores mencionaram ainda que a formação dos alunos nos cursos técnicos deve abordar também a discussão dos aspectos políticos da profissão e de seu exercício na sociedade, o que implica um ensino que vá além da transmissão de conhecimentos teóricos e práticos, preparando o aluno para uma atuação crítica no mundo do trabalho. Para Breno, isso pode ser feito por meio da discussão de artigos sobre posicionamentos de empresas em processo de produção, negociação e segurança no trabalho, bem como na criação de situações-problema para que os alunos solucionem como se fossem profissionais já atuantes nas empresas mineradoras. Segundo ele, essas estratégias de ensino possibilitam aos alunos reflexões sobre a ideologia das empresas e sobre as atitudes dos técnicos nas situações reais de trabalho. A postura desses dois professores, ao conferirem importância à formação mais crítica do aluno, está ligada à dimensão política do trabalho pedagógico que, para Masetto (1998), é uma das competências necessárias à docência. Para ele, o professor tem uma visão de homem, de mundo, de sociedade, de cultura, de educação e de trabalho que orienta suas ações e opções, e deve estar aberto ao que se passa na sociedade, às suas transformações e contradições, adotando uma postura crítica frente à realidade em seu trabalho docente. Essa dimensão política da prática possibilitaria que seu trabalho fosse articulado às demandas dos alunos de uma formação mais ampla, voltada não apenas para o desempenho de uma profissão, mas também para o seu posicionamento crítico frente aos determinantes históricos, sociais, políticos e econômicos do mundo do trabalho.

Os estudos sobre a formação docente para a EPT apontam que pouca importância tem sido conferida aos conhecimentos relacionados ao ensino para a atuação docente nessa modalidade, tanto no que se refere à legislação quanto à prática de contratação de professores para as escolas de EPT. No caso dessa pesquisa, três dos seis professores mencionaram o conhecimento pedagógico como importante para ensinar e consideram que esse tipo de conhecimento deve ser acrescentado ao conhecimento do conteúdo e ao conhecimento prático, mencionados anteriormente. Para os professores Rafael, Henrique e Vinícius, o conhecimento do conteúdo da área de formação deve estar aliado ao conhecimento pedagógico, que daria ao professor referências para transmitir os conteúdos de forma adequada à aprendizagem dos alunos. Ao abordarem a importância desse tipo de conhecimento, tais professores se referiram à possibilidade de o conhecimento pedagógico viabilizar "facilidade para transmitir o conteúdo" e "contribuir para saber enfrentar as dificuldades pedagógicas". Tais posicionamentos podem ser relacionados ao que Shulman (2005a) denomina de conhecimento pedagógico do conteúdo (CPC), ou seja, aquele tipo de conhecimento que engloba o conhecimento da matéria para ensiná-la, buscando maneiras adequadas para expor o conteúdo de forma que os alunos possam entendê-lo, usando analogias, descrições, exemplos, explicações e demonstrações. Os demais professores mencionaram tal tipo de conhecimento não de forma espontânea, mas sim quando questionados a respeito da importância da formação pedagógica para a prática docente na EPT.

Esse dado não deixa de causar certo estranhamento pois, ao falar sobre os desafios do início da carreira, os professores mencionaram a ausência de conhecimento pedagógico e assinalaram a importância de a instituição promover reuniões para discutir a prática de ensino e desenvolver projetos/atividades de capacitação voltados para a questão pedagógica. Quando questionados acerca de sua visão sobre a formação pedagógica, as percepções se diferenciaram para os sujeitos da pesquisa: "Acho que é importante, mas não é o principal. [...] Na área técnica, não é o mais importante" (Breno). Por outro lado, para Rafael, a formação pedagógica é "muito importante", pois pode dar ao professor mais segurança para enfrentar as situações que se apresentam no dia a dia, dando suporte às suas ações na sala de aula. Henrique e Vinícius consideram 


\section{autêntica}

importantes as contribuições da formação pedagógica e sugerem que a instituição realize investimentos em programas de capacitação para o ensino. Os dados mostram que, ao serem questionados sobre a relevância da formação pedagógica para sua prática, metade dos professores entrevistados a considera importante e reconhece a necessidade de que haja investimento da instituição nesse tipo de formação, mas não parece tão enfática como quando ao mencionar a formação na área específica do conhecimento do conteúdo ou do conhecimento prático. Percebe-se que, para os docentes, no conjunto dos conhecimentos necessários ao ensino, a relevância da formação pedagógica é destacada com menor ênfase, corroborando a pesquisa realizada por Gariglio e Burnier (2012), que apontou que, para os professores de EPT de diferentes instituições, "os saberes pedagógicos ocupam uma posição de menor status na hierarquia dos saberes necessários a ensinar" (GARIGLIO; BURNIER, 2012, p. 229).

Aliadas a essa pouca valorização do conhecimento pedagógico pelos professores, constatou-se, nas entrevistas, afirmações sobre a relevância da experiência da prática docente como forma de aquisição desse tipo de conhecimento. Consideram que a experiência como docente é que possibilitou-lhes adquirir aprendizagens que contribuíram para que fossem construindo a sua forma de ensinar, utilizando a vivência da prática docente, as dicas de colegas mais experientes e a reflexão sobre o trabalho desenvolvido para a introdução de mudanças em seus métodos. Para Rafael, um fator que se destacou e que contribuiu para que ele fosse adquirindo experiência foi a observação de seus colegas e a ajuda que recebeu deles por meio de dicas e materiais. Diferentes formas de lidar com os alunos e manejo para trabalhar com a diversidade deles, no entendimento de Leonardo, foram conhecimentos que a experiência Ihe possibilitou em sua trajetória profissional como professor. Henrique atribuiu ao tempo de experiência um valor significativo para a aprendizagem da docência, pois considera que esse fator viabiliza mais facilidade ao lidar com as novidades que surgem a cada ano. Em seu entendimento, o cotidiano vivenciado a cada ano possibilita a introdução de mudanças na prática, que são fruto da reflexão sobre o trabalho desenvolvido. Vinícius acredita que a experiência viabiliza maior domínio do conteúdo e entendimento da realidade dos alunos dos cursos técnicos integrados. Tal experiência, no seu entendimento, é construída tendo por base a análise de trabalhos anteriores que indicavam pistas para ir modificando a prática. Entretanto, isso era feito por meio de tentativas que nem sempre resultavam em sucesso no início da carreira. Um aspecto que se destaca nessas colocações é que os professores atribuem ao tempo a tarefa de fornecer conhecimentos sobre o ensino. Esse tempo parece ser usado no sentido de "tempo de experiência", período em que, no dia a dia da sala de aula, em interação com os alunos e os desafios da prática docente, buscam utilizar os conhecimentos advindos de diferentes espaços formativos, como a formação acadêmica, o trabalho em empresas e a experiência como aluno e professor, reelaborando-os e retraduzindo-os para construir uma determinada forma de desenvolver o trabalho docente. Essa forma inicial de ser professor parece ir se modificando a partir da própria experiência e das tentativas de mudança ou de continuidade no processo quando consideradas necessárias de acordo com a avaliação e a interpretação dos próprios professores, uma vez que eles não têm na instituição oportunidades de discussão coletiva sobre a prática. Diferentes estudos (TARDIF, 2008, SHULMAN,2005b, GHAUTIER et al., 1998, entre outros) apontam a relevância dos saberes da experiência, da sabedoria da prática ou do conhecimento prático como um componente importante na realização da prática docente. Entretanto, pode-se inferir que a ausência de formação pedagógica dos professores da EPT é um dos fatores que contribui para que eles atribuam grande importância ao conhecimento prático adquirido na experiência docente como relevante para a construção de conhecimentos sobre a docência. Reconhece-se que a aprendizagem pela experiência tem sua importância no processo de socialização profissional, mas torna-se necessário questionar a percepção dos professores de que apenas a experiência prática é suficiente para a aquisição desse tipo de conhecimento. Ela pode, e deve, a partir da reflexão, ser problematizada e reestruturada para articular-se a outros conhecimentos oriundos de diferentes fontes e ser enriquecida e ampliada com novos referenciais adquiridos em outros processos de formação. 


\section{autêntica}

\section{CONSIDERAÇÕES FINAIS}

A pesquisa mostrou que diferentes tipos de conhecimentos são importantes para subsidiar o ensino das disciplinas técnicas na EPT, apontando para o que pode ser chamado de uma escala de relevância atribuída a tais conhecimentos pelos entrevistados. O primeiro tipo de conhecimento mencionado pelos docentes é o conhecimento do conteúdo, aquele que oferece a compreensão necessária para o professor ensinar uma disciplina técnica, apontado como o requisito número um. Considera-se que esse tipo de conhecimento possibilita compreender o conteúdo a ser ensinado em uma perspectiva ampla, entender seu histórico de constituição e sua relação com as outras áreas que Ihe são afins, de forma a viabilizar um vasto entendimento da área de abrangência em que esse conhecimento se insere. Esse tipo de conhecimento precisa ser atualizado constantemente, o que garante ao professor o acompanhamento das mudanças tecnológicas, dos novos equipamentos e das alterações que ocorrem em sua área de atuação. Esse dado mostra que, embora diversos estudos apontem para um conjunto de conhecimentos que fundamentam o ensino, é o conhecimento do conteúdo que se mostra fundamental na docência das disciplinas técnicas, segundo os professores. Entretanto, conforme menciona Shulman (2005a) somente esse tipo de conhecimento não é suficiente para o ensino, é necessário que o professor detenha também o conhecimento pedagógico do conteúdo, aquele queque vai além do entendimento da matéria propriamente dita, pois engloba também o entendimento da matéria para ensiná-la (SHULMAN, 2005a, p. 212). É o tipo de conhecimento que, articulado com o conhecimento do conteúdo, confere ao professor a capacidade de transformar seu conhecimento da matéria em formas que sejam didaticamente adequadas para ensinar, atendendo à diversidade de habilidades e conhecimentos prévios dos alunos.

O segundo tipo de conhecimento destacado pelos professores foi o conhecimento prático, que foi adquirido por meio do trabalho anterior em empresas ou pelo desenvolvimento de projetos de pesquisa ou extensão na área de conhecimento na qual se insere o curso ou as disciplinas que ministram. Esse tipo de conhecimento foi mencionado pelos professores como aquele que Ihes viabiliza uma inserção no campo prático da formação que pretendem oferecer aos alunos, proporcionando-Ihes subsídios para exemplificar, ilustrar, propor atividades de análise de situações concretas e de aplicação prática dos conhecimentos em contexto real de trabalho na área de profissionalização pretendida. Os professores consideram que é esse tipo de conhecimento prático que enriquece o conhecimento do conteúdo, constituindo-se em uma fonte de exemplificação e ilustração das temáticas em estudo, viabilizando o estabelecimento da relação entre teoria e prática em sala de aula e a contextualização do ensino com o mundo do trabalho. No âmbito do conhecimento prático, as atividades de pesquisa e extensão também foram consideradas importantes para a prática docente na EPT, corroborando uma hipótese levantada por Kuenzer (2010), de que a pesquisa e a extensão, quando permitem a inserção no mundo do trabalho, "podem viabilizar uma relação práxica com a área de trabalho, que fundamente o trabalho pedagógico" (KUENZER, 2010, p. 506). Os dados indicam, ainda, que fatores como a atualização do professor com as novas tecnologias e ferramentas de trabalho do setor produtivo, sua clareza em relação às necessidades demandadas pela área em que atuará o futuro técnico, bem como o domínio do saber da prática profissional que ensina, ou seja, saber o que o aluno precisa aprender, foram considerados como bastante significativos para o ensino das disciplinas técnicas.

Um terceiro tipo de conhecimento mencionado foi o pedagógico, que, para os professores, deve estar articulado aos dois anteriores. É o conhecimento pedagógico que Ihes possibilita enfrentar as situações difíceis do início da carreira e ter mais facilidade para ensinar, contribuindo também para "ter mais segurança", "saber se portar em uma situação de ensino", "minimizar deficiências". Tais afirmações parecem indicar uma importância relativa desse tipo de conhecimento, pois essas expressões vieram após o questionamento 


\section{autêntica}

sobre o assunto e não espontaneamente durante os dizeres dos professores ao se referirem aos conhecimentos importantes para o ensino das disciplinas técnicas. Articulada a essa percepção, há a valorização do conhecimento da experiência docente como forma de aquisição do conhecimento pedagógico no decorrer da trajetória profissional. Constatou-se, assim, que é esse conjunto de conhecimentos, oriundos de diferentes espaços/situações, que fornece aos professores as condições para desenvolverem a prática docente na EPT, transformando em ensinável o seu conhecimento do conteúdo por meio de estratégias adequadas para a aprendizagem dos alunos, no dizer de Shulman (2005b).

Concordando com Kuenzer (2010, p. 514), não se pode desconsiderar a necessidade de o professor da EPT "ser um profundo conhecedor da sociedade do seu tempo, das relações entre educação, economia e sociedade, dos conteúdos específicos, das formas de ensinar e daquele que é a razão do seu trabalho: a aluno." Portanto, a docência na EPT implica um conjunto de saberes necessários ao ensino que não podem ser reduzidos ao conhecimento aprofundado de uma área específica, pois envolve também a necessidade de um conhecimento pedagógico que ultrapassa o domínio de uma área e demanda reflexão sobre a dimensão política e social da educação. Entretanto, na percepção dos professores entrevistados, é o conhecimento do conteúdo que assume importância primordial, aquele que fundamenta a constituição da prática docente na EPT.

A pesquisa revelou que houve uma articulação entre diferentes tipos de conhecimentos que convergiram para a construção de um repertório oriundo de diversos contextos, que forneceram subsídios para que os professores transformassem seus conhecimentos teóricos e práticos em instrumentos para a organização do seu trabalho docente. Na ausência da formação para o ensino, os professores fundamentaram-se em diferentes referências para organizar/construir o seu estilo de ensino e enfrentar os desafios da docência na EPT. Esses desafios poderiam ser enfrentados com mais segurança se os professores tivessem tido uma formação pedagógica, visto que a ausência dessa formação deixou uma lacuna que demandou a busca de outros referenciais para o desenvolvimento da prática docente. Essa prática foi decorrente também de outros fatores evidenciados nas entrevistas, como a preocupação com a aprendizagem dos alunos, a busca pessoal pela atualização de conhecimentos e pelo aperfeiçoamento profissional, o gosto pelo ensino e o desejo de melhorar como docente por meio da avaliação e reflexão sobre a própria prática, elementos que, em seu conjunto, apontam para o compromisso e para a preocupação dos professores em realizar um ensino de qualidade.

Uma análise realizada a partir de tais dados é a de que o fato de não terem tido formação para o ensino em seu percurso acadêmico e a reduzida oportunidade de vivenciar discussões sobre questões pedagógicas relacionadas à docência em sua trajetória profissional podem explicar, em parte, a pouca valorização do conhecimento pedagógico por esses professores. Outra análise interessante é a percepção de que, ainda que os professores valorizem de forma diferenciada os vários tipos de conhecimento, dando maior destaque ao conhecimento do conteúdo e àqueles oriundos da prática profissional no trabalho e menor ênfase aos conhecimentos pedagógicos, sua prática revela a articulação de conhecimentos de diferentes naturezas ao realizar seu trabalho cotidiano na docência.

Os resultados deste estudo indicam a necessidade de se reconhecer as singularidades da docência na EPT e apontam para uma compreensão mais alargada da formação docente para essa modalidade de ensino. Apontam ainda para a necessidade do profundo conhecimento do conteúdo para ensinar as disciplinas técnicas e reforçam a importância da formação pedagógica para os docentes, pois entende-se que essa, articulada aos demais elementos do processo formativo, pode contribuir para que vários desafios da prática docente sejam minimizados, evitando inseguranças e improvisações, principalmente no início da carreira. 


\section{autêntica}

A constatação de que a prática docente na EPT implica outras referências para além dos aspectos comumente identificados na formação docente em geral sugere um questionamento que possibilita reflexões sobre o tipo de formação adequada para os professores da EPT: os cursos de licenciatura, que são o espaço institucional e legal para a formação do professor no Brasil, tal como organizados atualmente, dariam conta de abarcar elementos tão distintos relacionados aos conhecimentos necessários para a docência na EPT? Essa é uma discussão já iniciada em nosso país, e diferentes autores ${ }^{10}$ têm questionado a pertinência do modelo das licenciaturas no sentido de proporcionar uma formação condizente com as demandas da EPT. Sendo assim, acredita-se ser necessário considerar, nas propostas de formação docente para a EPT, tanto inicial quanto continuada, não um enfoque prescritivo, mas baseado na possibilidade de discussão e reflexão sobre questões relacionadas ao ensino, tomando como ponto de partida o conhecimento das práticas docentes para vinculá-las a princípios teórico-metodológicos necessários ao desenvolvimento de uma educação profissional e tecnológica de qualidade.

Ao apontar conhecimentos básicos para a constituição da prática docente na EPT, a pesquisa apresenta aportes para aprofundar a problematização e a reflexão sobre a construção de conhecimentos sobre a docência nessa modalidade de ensino. Dessa forma, pode colaborar para fomentar o debate necessário à construção de políticas públicas de formação e profissionalização de professores da EPT, sobretudo nesse momento histórico-político em que a Rede Federal de Educação Profissional, Científica e Tecnológica vem passando por um processo de expansão em nosso país. 


\section{autêntica}

\section{REFERÊNCIAS}

ANDRÉ, M. Estudo de caso em pesquisa e avaliação educacional. Brasília: Liber Livro, 2005. (Série Pesquisa, v. 13).

ARANHA, A. V. S. Formação docente para a educação profissional: especificidades da área de saúde. Trabalho \& Educação, Belo Horizonte, v. 17, n. 3, p. 131-148, 2008.

ARAÚJO, R. M. L. A formação de professores para a educação profissional e tecnológica e a necessária atitude docente integradora. In: DALBEN, A. L.; DINIZ, J.; LEAL, L. de F. V.; SANTOS, L. (Org.). Convergências e tensões no campo da formação e do trabalho docente. Belo Horizonte: Autêntica, 2010. (Coleção Didática e Prática de Ensino).

BOGDAN, R.; BIKLEN, S. K. Investigação qualitativa em Educação: uma introdução à teoria e aos métodos. Tradução: Maria João Alvarez, Sara Bahia dos Santos e Telmo Mourinho Batista. Porto: Porto Editora, 1994.

BRASIL. Lei n. ${ }^{\circ} 11.741$, de 16 de julho de 2008. Altera dispositivos da Lei n. ${ }^{\circ 9.394, ~ d e ~} 20$ de dezembro de 1996, que estabelece as diretrizes e bases da educação nacional, para redimensionar, institucionalizar e integrar as ações da educação profissional técnica de nível médio, da educação de jovens e adultos e da educação profissional e tecnológica. Diário Oficial da União, Brasília, DF,17 jul. 2008. p. 5.

BRASIL. Ministério da Educação. Lei n. ${ }^{\circ}$ 9.394, de 20 de dezembro de 1996. Estabelece as Diretrizes e Bases da Educação Nacional. Diário Oficial da União, Brasília, 23 dez. 1996.

BRASIL. Ministério da Educação. Instituto Nacional de Estudos e Pesquisas Educacionais Anísio Teixeira (INEP). Sinopse estatística da Educação Básica 2013. Disponível em <http://portal.inep.gov.br/sinopses-estatisticas-da-educacao-basica> Acesso em 15 abr. 2015.

GARIGLIO, J. A.; BURNIER, S. Saberes da docência na educação profissional e tecnológica: um estudo sobre o olhar dos professores. Educação em Revista, Belo Horizonte, v. 28, n.1, p.211-236, mar. 2012.

GAUTHIER, C. et al. Por uma teoria da pedagogia: pesquisas contemporâneas sobre o saber docente. Tradução de Francisco Pereira. Ijuí: Ed. da UNIJUÍ, 1998.

KUENZER, A. Z. A formação de professores para a educação profissional e tecnológica. In: DALBEN, A. L.; DINIZ, J.; LEAL, L. de F. V.; SANTOS, L. (Org.). Convergências e tensões no campo da formação e do trabalho docente. Belo Horizonte: Autêntica, 2010. (Coleção Didática e Prática de Ensino).

KUENZER, A. Z.; FRANCO, M. C.; MACHADO, L. R. de S. Formação de professores para a educação profissional e tecnológica: perspectivas históricas e desafios contemporâneos. In: Formação de Professores para Educação Profissional e Tecnológica. Brasília: MEC/INEP, 2006.

MACHADO, L. R. de S. Diferenciais inovadores na formação de professores para a educação profissional. Revista Brasileira da Educação Profissional e Tecnológica, Brasília, v. 1, n. 1, jun. 2008.

MASETTO, M. (Org.). Docência na universidade. Campinas: Papirus, 1998. 


\section{DOCENTE}

\section{autêntica}

MELO, S. D. G. Trabalho docente na educação profissional. In: OLIVEIRA, D.A.; DUARTE, A. M. C.; VIEIRA, L. M. F. Dicionário: trabalho, profissão e condição docente. Belo Horizonte: UFMG/Faculdade de Educação, 2010. CD-ROM.

MOURA, D. H. A formação de docentes para a educação profissional e tecnológica. In: Simpósio Brasileiro de Política e Administração da Educação, 23, 2007, Porto Alegre. Anais... Porto Alegre: ANPAE, 2007.

OLIVEIRA, M. R. N. S. Mudanças no mundo do trabalho: Acertos e desacertos na proposta curricular para o Ensino Médio (Resolução CNE 03/98). Diferenças entre formação técnica e formação tecnológica. Educação \& Sociedade, ano 21, n. 70, abr. 2000.

OLIVEIRA, M. R. N. S. e BURNIER, S. Perfil das licenciaturas nos Institutos Federais de Educação, Ciência e Tecnologia. In: CUNHA, D. et al. (Org.). Formação/profissionalização de professores e formação profissional e tecnológica: fundamentos e reflexões contemporâneas. Belo Horizonte: Ed. da PUC Minas, 2013.

POUPART, J. et al. A pesquisa qualitativa: enfoques epistemológicos e metodológicos. 2. ed. Tradução de Ana Cristina Nasser. Petrópolis: Vozes, 2010.

REHEM, C. M. Estudo sobre o perfil do professor de educação técnica e contribuições para um projeto contemporâneo de formação docente no Brasil, numa perspectiva do trabalho e da educação no início do século XXI. Rio de Janeiro: UFRRJ, 2005. Dissertação (Mestrado em Educação Agrícola) - Programa de Pós-Graduação em Educação Agrícola, Universidade Federal Rural do Rio de Janeiro, Rio de Janeiro, 2005.

SHULMAN, L. S. El saber y entender del a profesión docente. Estudios Públicos, Santiago de Chile, n. 99, p. 196-224,2005a.

SHULMAN, L. S. Conocimiento y enseñanza: fundamentos de nueva reforma. Profesorado: Revista de curriculum y formación del profesorado. Granada, ES. Vol. 9. n. 2 - 2005b. Disponível em: <https://www.ugr. es/ recfpro/rev92ART1.pdf> Acesso em: 7 ago. 2010.

SILVA, M. A. Professores da educação profissional e tecnológica: formação, saberes e práticas profissionais. In: SANTOS, L. L. de C. P. e FAVACHO, A. M. P. (Org.). Políticas e práticas curriculares: desafios contemporâneos. Curitiba, PR, CRV, 2012.

TARDIF, M. Saberes docentes e formação profissional. 9. ed. Petrópolis: Vozes, 2008. 
